\title{
Criptococose associada à AIDS. A importância do cultivo da urina no seu diagnóstico
}

\author{
Importance of culture of urine in the diagnosis of AIDS \\ associated cryptococcosis
}

\author{
Vitor Laerte Pinto Junior ${ }^{1}$, Maria Clara Gutierrez Galhardo², Márcia Lazéra², \\ Bodo Wanke ${ }^{2}$, Rosani Santos Reis ${ }^{2}$ e Maurício Perez ${ }^{3}$
}

\begin{abstract}
RESUMO
Neste estudo retrospectivo analisamos 70 pacientes HIV positivos com criptococose em um período de 16 anos. Os espécimes com melhor rendimento diagnóstico foram o LCR (97,8\%), seguido do cultivo do sedimento urinário (86,7\%) e sangue $(58,8 \%)$. Concluímos que a urina pode ser uma ferramenta útil para o diagnostico da criptococose.
\end{abstract}

Palavras-chaves: Criptococose. Síndrome da imunodeficiência adquirida. Diagnóstico. Urina. Cryptococcus neoformans.

\begin{abstract}
In this retrospective study we analyzed $70 \mathrm{HIV}$ patients with cryptococcosis over a 16-years period. The specimens with the best positivity were CSF (97.8\%) followed by the culture of urine sediment (86.7\%) and blood culture (58.8\%). We conclude that the urine could be a useful tool for the diagnosis of cryptococcosis.
\end{abstract}

Key-words: Cryptococcosis. Acquired immunodeficiency syndrome. Diagnosis. Urine. Cryptococcus neoformans.

A criptococose é a micose de caráter sistêmico mais freqüente em pacientes com $\operatorname{AIDS}^{6} \mathrm{e}$ a terceira causa de doença oportunista do sistema nervoso central (SNC). Sua prevalência varia de 2,9 a $13,3 \%$ representando importante causa de mortalidade na AIDS, apesar do tratamento específico ${ }^{345}$.

A maior parte dos casos de criptococose é diagnosticada como meningoencefalite de caráter insidios $0^{8}$, tendo febre como manifestação/sintoma mais freqüente, ao lado das relacionadas ao acometimento do sistema nervoso central como cefaléia, vômitos e queda do estado de consciência ${ }^{11}$, presentes em cerca da metade dos casos. A inespecificidade das manifestações clínicas acarreta muitas vezes em atraso no diagnóstico e contribui para a gravidade da doença.

Com o objetivo de avaliar os principais espécimes clínicos que evidenciaram Cryptococcus neoformans ao exame microscópico direto e/ou no isolamento em cultivo e que levaram ao diagnóstico da micose, foi realizado um estudo retrospectivo de série de casos de pacientes HIV positivos, atendidos no Instituto de Pesquisa Clínica Evandro Chagas (IPEC) da Fundação Oswaldo Cruz/RJ(FIOCRUZ).
Foram incluídos todos os pacientes comprovadamente HIV positivos que apresentaram espécime clínico com isolamento de $C$. neoformans no laboratório de micologia, ou resultado de exame histopatológico, acompanhados no IPEC no período de 1987 a 2002.

Os pacientes foram estratificados nas seguintes formas clínicas:

- Forma disseminada com meningite: caracterizada pela presença do fungo no líquor.

- Forma Disseminada sem meningite: caracterizada pela presença do fungo em amostras de urina (exame direto e cultura) e/ou sangue (hemocultura), com exame liquórico negativo (direto e cultura).

- Forma disseminada com líquor não testado: forma de exceção, quando não foi realizado o exame micológico do líquor.

- Colonização: espécimes de escarro positivos para o fungo e negativo para os outros espécimes (principalmente líquor, sangue e urina).

\footnotetext{
1. Centro de Estudos do Instituto Estadual de Infectologia São Sebastião, Rio de Janeiro, RJ, 2. Laboratório de Micologia Médica do Instituto de Pesquisa Clínica Evandro Chagas da Fundação Oswaldo Cruz, Rio de Janeiro, RJ. 3. Núcleo de Estudos em Saúde Coletiva da Universidade Federal do Rio de Janeiro, Rio de Janeiro, RJ.

Endereço para Correspondência: Dr. Vitor Laerte Pinto Jr. R. Carlos Seidl 395, Caju, 20931-003 Rio de Janeiro, RJ.

Tel: $55212580-0868$

e-mail: vitorlaerte@terra.com.br

Recebido para publicação em 10/2/2005

Aceito em 27/1/2006
} 
No período, foram diagnosticados 73 casos de pacientes que evidenciaram o $C$. neoformans em algum espécime clínico, três casos de diagnóstico em exclusivo de necropsia foram excluídos. Dos 70 pacientes incluídos 58 (82,9\%) eram do sexo masculino e $12(17,1 \%)$ eram mulheres, apresentando idade média de 37 anos. Quanto ao comportamento de risco para exposição ao HIV, 39 (55,7\%) pacientes referiram comportamento homo ou bissexual, $22(31,4 \%)$ comportamento heterossexual, 5 (7,1\%) diziamse usuários de drogas intravenosas e $2(2,9 \%)$ pacientes afirmaram que foram infectados através de hemotransfusão. Em $2(2,9 \%)$ casos não foi possível se definir esta variável.

A criptococose foi a primeira doença oportunista para $11(15,7 \%)$ dos pacientes, que no momento da internação, apresentavam linfometria T CD4 média de 40 células $/ \mathrm{mm}^{3}$. A frequiência das formas clínicas e a positividade de diversos espécimes testados para cada uma estão ilustradas na Tabela 1.

A frequiência das formas clínicas observadas foi semelhante à de outros estudos, como a disseminada com meningite de 75 a $86 \%$ e a criptoccocemia sem invasão/disseminação para 0 SNC, na ordem de $15 \%{ }^{13513}$. 0 espécime clínico mais colhido e com melhor rendimento $(97,8 \%)$ foi o LCR, refletindo o tropismo de $C$. neoformans para o SNC, seguido da urina, com $71,6 \%$. A urina revelou ser o espécime clínico mais importante para o diagnóstico da forma disseminada sem acometimento meníngeo $(86,7 \%)$ e o segundo mais importante com acometimento meníngeo $(64,9 \%)$ sendo inclusive superior à hemocultura $(58,8 \%)$. Estes resultados contrastam com estudos prévios que encontraram uma frequiência de isolamento do $C$. neoformans na urina em torno de $40 \%$, mesmo em pacientes com AIDS $^{124}$ e outros de 8 a $10 \%{ }^{8}$. Estes estudos empregaram o meio Sabouraud para isolamento do $C$. neoformans. Os nossos achados refletem a rotina diagnóstica implantada na instituição: coleta de três amostras de urina de todos pacientes com AIDS e febre, para avaliação específica quanto à presença de $C$. neoformans. Em relação à hemocultura, a frequiência de isolamento com a técnica de lise centrifugação em pacientes com AIDS apresenta uma sensibilidade de $70 \%$, superior à observada neste estudo ${ }^{12}$. Esta técnica não foi utilizada em todas as amostras. 0 exame de escarro, realizado em 20 pacientes, apresentou positividade máxima de $16,7 \%$ revelando que o pulmão, como porta de entrada da infecção, constitui um alvo para diagnóstico, mas de rendimento bem menor que os espécimes de urina na presente casuística, onde predomina a forma disseminada. Outros espécimes revelaram $C$. neoformans, confirmando que o fungo pode infectar qualquer órgão, em especial a pele e a próstata, visto em 7 dos 70 casos.

0 acometimento genitourinário na criptococose, tal como pielonefrite, lesões do trato genitourinario baixo, é considerado raro ${ }^{8}$. Com relação à próstata, a infecção por C. neoformans não causa sintomas de prostatite, mas o agente pode ser isolado do tecido prostático ocasionalmente. A presença desta levedura na urina, sem evidência de lesão no trato urinário, pode ser relacionada à fungemia, seguida de passagem pelo endotélio vascular e membrana basal glomerular, alcançando o filtrado tubular, onde encontra progressivamente elevada osmolaridade e concentração de uréia e creatinina, condições metabólicas particularmente favoráveis à sua reprodução. A presença de fungos na urina de pacientes com fungemia já foi observada também em outras micoses sistêmicas como a coccidioidomicose $e^{9}$. Outro aspecto a considerar é o meio de cultivo utilizado para urina, geralmente Sabouraud-glicose $2 \%$ sem cicloheximida, onde C. neoformans forma colônias lisas em tons de cor creme o que não permite a diferenciação visual de múltiplas colônias similares de outras leveduras e bactérias. Um diferencial importante em nosso trabalho foi o uso de meio ágar com sementes de niger para urinocultura (meio NSA), que permite discriminar um número mínimo de colônias de $C$. neoformans em meio a muitos outros microrganismos pela cor marrom escura. Neste caso, o meio NSA funciona como meio seletivo e indicador ${ }^{10}$, baseado na capacidade de $C$. neoformans de produzir melanina quando cultivado em substratos contendo produtos difenólicos, devido à ação de uma fenol-oxidase,

Tabela 1 - Espécimes clínicos que evidenciaram Cryptococcus neoformans e sua associação com as formas clínicas em 70 pacientes soropositivos para o HIV.

\begin{tabular}{|c|c|c|c|c|c|c|c|c|}
\hline \multirow[b]{4}{*}{ Espécime } & \multicolumn{4}{|c|}{ Forma clínica } & & & \multirow{3}{*}{\multicolumn{2}{|c|}{$\begin{array}{l}\text { colonização do } \\
\text { trato respiratório } \\
\qquad(\mathrm{n}=4)\end{array}$}} \\
\hline & \multirow{2}{*}{\multicolumn{2}{|c|}{$\begin{array}{l}\text { com meningite } \\
\qquad(\mathrm{n}=47)\end{array}$}} & \multicolumn{2}{|c|}{ disseminada } & & & & \\
\hline & & & \multicolumn{2}{|c|}{$\begin{array}{l}\text { sem meningite } \\
\qquad(\mathrm{n}=16)\end{array}$} & \multicolumn{2}{|c|}{$\begin{array}{l}\text { indefinida } \\
\qquad(\mathrm{n}=3)\end{array}$} & & \\
\hline & pos total & $\%$ & pos \total & $\%$ & pos \total & $\%$ & pos \total & $\%$ \\
\hline Líquor/cultura & $45 \backslash 46$ & 97,8 & $0 \backslash 14$ & - & - & - & -13 & - \\
\hline Líquor/ex direto & $36 \backslash 45$ & 80,0 & $0 \backslash 14$ & - & - & - & -14 & - \\
\hline Urinocultura & $24 \backslash 37$ & 64,9 & $13 \backslash 15$ & 86,7 & $1 \backslash 1$ & 100,0 & - & - \\
\hline Urina/ex direto & $13 \backslash 37$ & 35,1 & $6 \backslash 15$ & 40,0 & $1 \backslash 1$ & 100,0 & - & - \\
\hline Hemocultura & $20 \backslash 34$ & 58,8 & $6 \backslash 13$ & 46,2 & $3 \backslash 3$ & 100,0 & -14 & - \\
\hline Pele/cultura & 419 & 44,4 & - & - & - & - & - & - \\
\hline Pele/ex direto & $1 \backslash 10$ & 10,0 & - & - & - & - & - & - \\
\hline Medula óssea/ cultura & $2 \backslash 5$ & 40,0 & $2 \backslash 4$ & 50,0 & - & - & - & - \\
\hline Escarro/cultura & $3 \backslash 14$ & 21,4 & $1 \backslash 6$ & 16,7 & - & - & 414 & 100,0 \\
\hline Escarro/ex direto & $1 \backslash 14$ & 7,1 & $0 \backslash 10$ & - & - & - & $2 \backslash 5$ & 40,0 \\
\hline Urina pós-massagem prostática & $-\backslash 1$ & - & $2 \backslash 2$ & 100,0 & - & - & - & - \\
\hline
\end{tabular}

pos = positivos; ex= exame; - = não realizado ou nulo 
enzima considerada de fundamental importância para sua identificação e virulência.

Recentemente, a presença de C.neoformans na urina foi evidenciada em 16 pacientes num período de estudo de 12 anos. Destes, $81 \%$ apresentavam a forma disseminada, confirmando a sua importância no diagnóstico precoce da micose. Entretanto, o meio de NSA não foi utilizado ${ }^{7}$.

No presente estudo, a realização de exame micológico rotineiro da urina semeada em meio de NSA se mostrou de grande utilidade para o diagnóstico da criptococose, principalmente porque é de mais fácil obtenção e menor risco biológico quando comparado ao sangue e ao LCR. Recomendamos coleta de urina matinal em três dias consecutivos e cultivando-a em meio NSA, como procedimento rotineiro diagnóstico de febre em pacientes com aids. Este recurso simples e de baixo custo deve ser lembrado também como alternativa para os casos ambulatoriais e de hospitaldia nos quais pode ser difícil realizar coleta de amostras para hemocultura.

\section{REFERÊNCIAS BIBLIOGRÁFICAS}

1. Antinori S, Galimberti L, Magni C, Casella A, Vago L, Mainini F, Piazza M, Nebuloni M, Fasan M, Bonaccorso C, Vigevani GM, Cargnel A, Moroni M, Ridolfo A. Cryptococcus neoformans infection in a cohort of Italian AIDS patients: natural history, early prognostic parameters, and autopsy findings. European Journal of Clinical Microbiology \& Infectious Diseases 20:711$717,2001$.

2. Arechavala AI, Robles AM, Negroni R, Bianchi MH, Taborda A. Value of direct and indirect diagnostic methods in systemic mycoses associated with AIDS. Revista do Instituto de Medicina Tropical de Sao Paulo 35:163-169, 1993

3. Chuck SL, Sande MA. Infections with Cryptococcus neoformans in the acquired immunodeficiency syndrome. New England Journal of Medicine 321:794-799, 1989.

4. Clark RA, Greer D, Atkinson W, Valainis GT, Hyslop N. Spectrum of Cryptococcus neoformans infection in 68 patients infected with human immunodeficiency virus. Reviews of Infectious Diseases 12:768-777, 1990.

5. Darras-Joly C, Chevret S, Wolff M, Matheron S, Longuet P, Casalino E, Joly V, Chochillon C, Bedos JP. Cryptococcus neoformans infection in France: epidemiologic features of and early prognostic parameters for 76 patients who were infected with human immunodeficiency virus. Clinical Infectious Diseases 23:369-376, 1996.

6. Dismukes WE. Cryptococcal meningitis in patients with AIDS. Journal of Infectious Diseases 157:624-628, 1988.

7. Kiertiburanakul S, Sungkanuparph S, Buabut B, Pracharktam R. Cryptococcuria as a manifestation of disseminated cryptococcosis and isolated urinary tract infection. Japanese Journal of Infectious Diseases 57:203-205, 2004.

8. Perfect JR, Casadevall A. Cryptococcosis. Infectious Diseases Clinics of North America 16:837-874, v-vi, 2002.

9. Petersen EA, Friedman BA, Crowder ED, Rifkind D. Coccidoidouria: clinical significance. Annals of Internal Medicine 85:34-38, 1976.

10. Staib F. On The Creatin-Creatinine Assimilation In Yeast-Fungus Diagnosis. Zentralblatt fur Bakteriologie 191:429-432, 1963.

11. Sugar AM. Overview: cryptococcosis in the patient with AIDS Mycopathologia 114:153-157, 1991.

12. Yagupsky P, Menegus MA. Cumulative positivity rates of multiple blood cultures for Mycobacterium avium-intracellulare and Cryptococcus neoformans in patients with the acquired immunodeficiency syndrome. Archives of Pathology \& Laboratory Medicine 114:923-925, 1990.

13. Zuger A, Louie E, Holzman RS, Simberkoff MS, Rahal JJ. Cryptococcal disease in patients with the acquired immunodeficiency syndrome. Diagnostic features and outcome of treatment. Annals of Internal Medicine 104:234-240, 1986. 